\title{
Papillary Thyroid Cancer Affecting Multiple Family Members: A Case Report and Literature Review of Familial Nonmedullary Thyroid Cancer
}

\author{
Khaled Ahmed Baagar $(1)$ and Buthina Ibrahim Alowainati \\ Endocrine Department, Hamad Medical Corporation, Doha, P.O. Box 3050, Qatar \\ Correspondence should be addressed to Khaled Ahmed Baagar; kbaagar@hamad.qa
}

Received 18 June 2021; Accepted 7 October 2021; Published 15 October 2021

Academic Editor: Wayne V. Moore

Copyright ( 2021 Khaled Ahmed Baagar and Buthina Ibrahim Alowainati. This is an open access article distributed under the Creative Commons Attribution License, which permits unrestricted use, distribution, and reproduction in any medium, provided the original work is properly cited.

\begin{abstract}
Familial nonmedullary thyroid cancer (FNMTC) represents 5-10\% of NMTC cases. Many controversies are associated with the FNMTC, namely, the minimum required number of affected family members to define the condition, aggressiveness, prognosis, and treatment and screening recommendations. Moreover, the genetic basis of the FNMTC has not yet been identified. We report a family diagnosed with FNMTC and present a comprehensive literature review of the condition. The index case was a 26-year-old male who was diagnosed with locally advanced papillary thyroid cancer (PTC). Then, his family members became worried and asked for a neck ultrasound. Four of his six siblings, in addition to his father, were diagnosed with PTC. In addition, two of his cousins were diagnosed. The patient underwent total thyroidectomy with bilateral neck dissection, and he received 2 doses of radioactive iodine (100 $\mathrm{mCi}$ each). Furthermore, one of his siblings required a second surgery with repeated radioactive iodine therapy. The index case genetic screening and whole-exome sequencing did not show any abnormalities. Future genetic and clinical research should focus on kindred with 3 or more affected individuals for better identification of the FNMTC susceptibility genes and to better guide management and screening recommendations.
\end{abstract}

\section{Introduction}

Papillary thyroid cancer (PTC) is the most common primary thyroid malignancy and accounts for more than $80 \%$ of thyroid cancers [1]. Most PTC cases are sporadic; however, $5-10 \%$ are familial $[2,3]$, and like the sporadic form, females are 2-3 times more affected than males [4-6]. Familial PTC (FPTC) is the most common type of familial nonmedullary thyroid cancer (FNMTC) [7], which is identified, in most studies, when two or more first-degree relatives are diagnosed with the condition in the absence of a history of familial syndromes or risk factors that are commonly associated with NMTC [8-11].

We report a family which was diagnosed with FPTC after the index case (i.e., the first case had been diagnosed in the family) had been diagnosed with a locally advanced PTC. In addition, in this report, we reviewed the topic of FNMTC with its associated controversies in definition, aggressiveness in comparison to sporadic NMTC (SNMTC), latest information about the genetic background, prognosis, screening and management recommendations, and future research requirements to improve our knowledge about the condition.

\section{Case Presentation}

In February 2015, a 26-year-old male presented to the emergency department with generalized muscle weakness for 1 day. On physical examination, he had normal vital signs except for a pulse rate of $105 /$ minute, a muscle power of $3 / 5$ throughout his extremities, and a multinodular goiter with bilateral cervical lymphadenopathy. His laboratory workup was significant for potassium: $1.8 \mathrm{mmol} / \mathrm{L}$ (normal: 3.6-5), TSH: $<0.01 \mathrm{mIU} / \mathrm{L}$ (normal: $0.45-4.5$ ), FT4: $22.2 \mathrm{pmol} / \mathrm{L}$ (normal: 9-20), and FT3: $10 \mathrm{pmol} / \mathrm{L}$ (normal: 3.4-6). His muscle power improved with potassium replacement. A thyroid uptake scan showed increased uptake 
with a cold thyroid nodule. Therefore, carbimazole and propranolol were prescribed.

Neck ultrasound and magnetic resonance imaging showed $1.6 \mathrm{~cm}$ and $1.2 \mathrm{~cm}$ nodules with calcifications in the right thyroid lobe, with evidence of bilateral lymph node metastases and bilateral extranodal soft tissue metastases. CT chest to assess mediastinal lymphadenopathy or lung metastases was unremarkable. Fine-needle aspiration biopsy (FNAB) from a lymph node metastasis in the neck showed metastatic PTC. Then, FNAB from the right thyroid nodules was performed, and it showed PTC.

The patient underwent total thyroidectomy and bilateral neck dissection. Two foci $(2 \mathrm{~cm}$ and $1 \mathrm{~cm})$ of classical PTC were found in the right thyroid lobe with lymph node involvement and extranodal metastases. Thereafter, $\mathrm{I}^{131}$ $100 \mathrm{mci}$ was given, and the postablation scan showed a remnant in the left thyroid bed (TNM staging: T4aN1bM0 tumor).

The patient's family was worried about themselves and asked for a thyroid evaluation. The patient's brother, in addition to 3 of his 5 sisters, was found to have PTC (see details in Table 1). The remaining 2 sisters (aged 22 and 29 years) and the mother (aged 52 years) underwent a normal initial thyroid ultrasound scan, and then the yearly ultrasound surveillance was unremarkable. The father (aged 55 years) was found to have a thyroid nodule; however, he was reluctant to have FNAB until January 2018 at another institution where he was diagnosed with thyroid cancer, but we do not have any data about his follow-up there (see family pedigree in Figure 1).

There were no other cancers or clinical features indicating a familial syndrome in the family. The patient's genetic screening was negative for pathogenic variants of the PARP4, APC, DICER1, RET, SDHB, and SDHD genes. In addition, the patient underwent whole-exome sequencing, which was unremarkable.

After more than 6 years of follow-up of the index case and his family, two of them, including himself, had a recurrence and required further treatment (see Table 1). In addition, he reported to us that 2 of his paternal cousins, who were not siblings, had developed thyroid cancer.

\section{Discussion}

In 1955, Robinson and Orr presented the first evidence of the familial clustering of NMTC, where they reported PTC in 2 monozygotic twins [12].

Many controversies are related to the FNMTC, starting from its definition to clinical behavior, outcomes, management recommendations, and screening of the patients' family members. This controversy is mainly because of the small number of studies of FNMTC, mostly retrospective, and their relatively small number of subjects because of the low disease prevalence. In addition, the follow-up duration in these studies was short relative to the nature of the disease.

There is no consensus on whether two $[2,9,13,14]$ or three [15-18] first-degree relatives of a family are the minimum required number to define FNMTC, as SNMTC is very common and it can affect more than one individual in a family. Charkes [5] found that in families with 2 affected individuals, $62-69 \%$ of the cases are sporadic, while in families with $\geq 3$ affected members, less than $6 \%$ of the cases are sporadic. In one study, it was found that $4.6 \%$ of at-risk individuals had thyroid cancer in families with 2 affected members, while $22.7 \%$ of at-risk individuals were affected in the families with $\geq 3$ affected members [19].

Despite the recommendation to consider mainly families with $\geq 3$ affected members for clinical and genetic analyses [5], most of the reports are mainly based on families with 2 affected cases. The family we described in this report, with 6 affected first-degree relatives, has very strong evidence of FNMTC.

3.1. Histopathological Features. From a histological viewpoint, there is no specific feature that distinguishes FNMTC from SNMTC [20], except in one report which showed that patients in the FNMTC group had more significantly classic variant PTC than those in the sporadic PTC group (84\% vs. $63.3 \% ; P<0.001)$ [7]. We found that all the affected individuals in the reported family had classic variant PTC, except one who had a follicular variant PTC.

3.2. Clinical Aggressiveness at Presentation. It is the most controversial part, as some studies have shown that FNMTC demonstrates a more aggressive presentation than SNMTC, such as earlier onset, bilateral and multifocal tumors, extrathyroidal invasion, and lymph node metastasis [9, 14, 21-28].

Recently, El Lakis et al. reported that FNMTC patients were diagnosed at an earlier age ( $62 \%$ vs. $49.5 \%$; $P=0.041)$, with a higher rate at the T1 stage $(75 \%$ vs. $57.8 \% ; P=0.01)$ and a higher rate of lymph node involvement $(P=0.002)$ [7].In addition, Sezer et al. found that both FPTC and sporadic PTC (SPTC) groups had no difference in age at presentation or tumor size; however, the familial group was found to have more aggressive features, such as higher rates of multifocal tumors $(P=0.011)$, bilateral involvement $(P=0.004)$, extrathyroid extension $(P=0.040)$, and lymph node metastasis $(P=0.013)$ [29]. Furthermore, Kim YS et al. reported more multifocality $(P=0.020)$, benign thyroid nodules $(P=0.015)$, and lateral neck lymph node involvement $(P=0.021)$ in the FNMTC group [10].

The reported family had 6 affected members, with 2 of them (the index case and sibling 3) showing the most aggressive features such as multifocality, capsular invasion, extrathyroid extension, vascular/lymphatic invasion, and lymph node involvement and sibling 3 showing bilateral disease.

Even those with familial papillary microcarcinoma, when compared to their sporadic counterparts, had more multifocal tumors (71\%), more vascular invasion (43\%), and a higher rate of lymph node involvement (57\%) [30]. In the reported family, only sibling 4 had a microscopic PTC with no aggressive features.

On the other hand, a good number of studies did not show any difference in clinical aggressiveness at presentation between FNMTC and SNMTC patients [1, 6, 18, 31-33]. 
TABLE 1: Characteristics of the diagnosed thyroid cancer in the family members.

\begin{tabular}{|c|c|c|c|c|c|c|}
\hline & Index case & Sibling 1 & Sibling 2 & Sibling 3 & Sibling 4 & Father \\
\hline $\begin{array}{l}\text { Age at diagnosis } \\
\text { (years) }\end{array}$ & 26 & 30 & 23 & 29 & 33 & 58 \\
\hline Gender & Male & Male & Female & Female & Female & Male \\
\hline $\begin{array}{l}\text { Nodular } \\
\text { goiter }( \pm)\end{array}$ & + & - & - & + & + & \\
\hline $\begin{array}{l}\text { Tumor diameter } \\
(\mathrm{cm})\end{array}$ & 2.0 & 1.0 & 2.2 & 2.6 & 0.12 & \\
\hline $\begin{array}{l}\text { Histological } \\
\text { variant of PTC }\end{array}$ & Classic & Classic & Classic & Classic & Follicular & \\
\hline $\begin{array}{l}\text { Laterality } \\
\text { (unilateral/ } \\
\text { bilateral) }\end{array}$ & Unilateral & Unilateral & Unilateral & Bilateral & Unilateral & \\
\hline $\begin{array}{l}\text { Focality } \\
\text { (unifocal/ } \\
\text { multifocal) }\end{array}$ & Multifocal & Unifocal & Unifocal & Multifocal & Unifocal & \\
\hline $\begin{array}{l}\text { Capsule } \\
\text { invasion }( \pm)\end{array}$ & + & + & - & + & - & \\
\hline $\begin{array}{l}\text { Extrathyroid } \\
\text { extension }( \pm)\end{array}$ & + & - & - & + & - & \\
\hline $\begin{array}{l}\text { Vascular/ } \\
\text { lymphatic } \\
\text { invasion }\end{array}$ & + & - & - & + & - & \\
\hline $\begin{array}{l}\text { Hashimoto's } \\
\text { thyroiditis }( \pm)\end{array}$ & - & - & + & - & - & \\
\hline $\begin{array}{l}\text { Central LN } \\
\text { involvement }( \pm)\end{array}$ & + & - & - & + & - & \\
\hline $\begin{array}{l}\text { Lateral LN } \\
\text { involvement }( \pm)\end{array}$ & + & Not sampled & Not sampled & Not sampled & Not sampled & \\
\hline $\begin{array}{l}\text { Distant } \\
\text { metastasis }( \pm)\end{array}$ & - & - & - & - & - & \\
\hline $\begin{array}{l}\text { pTNM } \\
\text { classification }\end{array}$ & T4aN1bM0 & T1aN0M0 & T2N0M0 & T3bN1aM0 & TlaN0Mx & \\
\hline $\begin{array}{l}\text { Surgical } \\
\text { procedures }\end{array}$ & $\begin{array}{l}\text { Total thyroidectomy } \\
\text { with bilateral neck } \\
\text { dissection }\end{array}$ & $\begin{array}{c}\text { Total } \\
\text { thyroidectomy } \\
\text { with central LN } \\
\text { dissection }\end{array}$ & $\begin{array}{c}\text { Total } \\
\text { thyroidectomy } \\
\text { with central LN } \\
\text { dissection }\end{array}$ & $\begin{array}{c}\text { Total thyroidectomy } \\
\text { with central LN } \\
\text { dissection }\end{array}$ & $\begin{array}{c}\text { Total } \\
\text { thyroidectomy } \\
\text { with central LN } \\
\text { dissection }\end{array}$ & \\
\hline $\begin{array}{l}\text { RAI ablation } \\
\text { and dose }\end{array}$ &,$+ 100 \mathrm{mCi}$ &,$+ 100 \mathrm{mCi}$ & 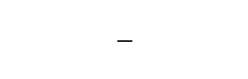 &,$+ 30 \mathrm{mCi}$ & - & \\
\hline $\begin{array}{l}\text { Persistence/ } \\
\text { recurrence of the } \\
\text { disease }( \pm)\end{array}$ & + & - & - & + & - & \\
\hline $\begin{array}{l}\text { Repeated } \\
\text { treatment } \\
\text { (surgery and/or } \\
\text { RAI and dose) }\end{array}$ & $\begin{array}{l}\text { In February } 2017 \text {, he } \\
\text { received a } 2 \text { nd dose of } \\
\text { RAI ( } 100 \mathrm{mCi} \text { ) for } \\
\text { local recurrence in the } \\
\text { thyroid bed }\end{array}$ & - & - & $\begin{array}{l}\text { In April 2019, surgery } \\
\text { for thyroid recurrence } \\
\text { with bilateral neck } \\
\text { dissection and RAI } \\
(100 \mathrm{mCi})\end{array}$ & - & \\
\hline $\begin{array}{l}\text { Death from the } \\
\text { disease }( \pm)\end{array}$ & - & - & - & - & - & - \\
\hline $\begin{array}{l}\text { Duration of } \\
\text { follow-up }\end{array}$ & $\begin{array}{c}\text { Since April } 2015 \text { (75 } \\
\text { months) }\end{array}$ & $\begin{array}{l}\text { Since July } 2015 \\
\text { (72 months) }\end{array}$ & $\begin{array}{l}\text { Since November } \\
2015 \text { (68 months) }\end{array}$ & $\begin{array}{c}\text { Since May } 2016 \text { (62 } \\
\text { months) }\end{array}$ & $\begin{array}{l}\text { Since August } 2015 \\
\text { (71 months) }\end{array}$ & $\begin{array}{c}\text { Since } \\
\text { January } \\
2018(42 \\
\text { months) }\end{array}$ \\
\hline
\end{tabular}

PTC: papillary thyroid cancer, LN: lymph node, and RAI: radioactive iodine. Note. There were no data about the father's tumor, as he had the management and follow-up data outside our institution.

Most studies, whether they showed or did not show that FNMTC was more aggressive than SNMTC, did not show a difference in the rate of distant metastasis. However, Sezer et al. reported a higher rate in the familial group $(P \leq 0.0001)$ [29], and McDonald et al. [34] found that the FNMTC group had more distant metastasis (8.8\%) than the SNMTC group (3.1\%) $(P=0.003)$, with more aggregation of the cases in some families with $\geq 3$ affected members.

Some studies have tried to investigate whether there is any difference in the clinical behavior of the FNMTCs when 


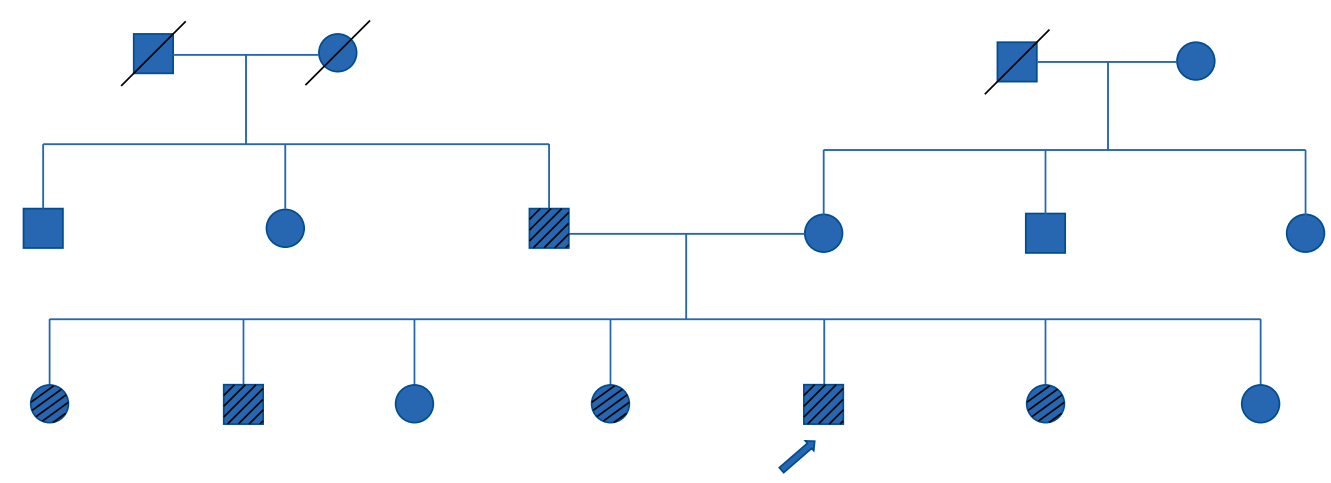

FiguRE 1: Family pedigree. Squares represent male family members; circles represent female family members; multiple-slashed symbols represent affected members; single-slashed symbols represent deceased members. The arrow points to the proband.

only 2 first-degree relatives are affected and when $\geq 3$ firstdegree relatives are affected. In the study performed by Zhang et al. [9], the FNMTC subgroup with 2 affected members had more significant multifocal tumors than the SNMTC group. The FNMTC subgroup with $\geq 3$ affected members had more significant thyroid nodular goiter and bilateral and multifocal tumors with extrathyroid extension and lateral lymph node metastasis than both the SNMTC group and the FNMTC subgroup with 2 affected members. On the other hand, Pinto et al. [13] showed that the FNMTC subgroup with $\geq 3$ affected members had no difference from the SNMTC group regarding the clinicopathological features or DNA ploidy, with only a nonsignificant tendency for extrathyroid invasion in that subgroup. In addition, McDonald et al. [34] showed no difference in almost the same surgical pathology features between the SNMTC, 2member FNMTC, and $\geq 3$-member FNMTC groups.

In more recent studies, El Lakis et al. found no difference between the FNMTC subgroup of 2 affected members and either the SNMTC group or the FNMTC subgroup of $\geq 3$ affected members; however, the latter group presented at a younger age $(P=0.04)$ and had more lymph node metastasis $(P=0.009)$ than the SNMTC group [7]. On the other hand, Sezer et al. showed that the 2-member FPTC group, in comparison to the SPTC group, had more significant bilaterality, multifocality, extrathyroid extension, and distant metastasis [29]. The $\geq 3$-member FPTC group, in comparison to the SPTC group, had more distant metastasis and less extrathyroid extension [29]. The comparison of the 2 -member FPTC group and the $\geq 3$-member FPTC group showed that the former had more vascular invasion and extrathyroid extension and lower rates of bilaterality, lymphatic invasion, and distant metastasis [29].

A meta-analysis of 6 retrospective studies, with a relatively small number of subjects, comparing the clinicopathological features between the first and second generations in families with FNMTC found that secondgeneration patients tend to be younger, male, and have a higher risk of lymph node metastasis. However, there was no difference in tumor size, multifocality, or extrathyroid invasion [8].

One study tried to compare 2 subtypes of FNMTC, namely, parent-offspring type and sibling type versus each other and versus SNMTC [27]. When compared to SNMTC, the sibling FNMTC group had more females, smaller tumor size, and more combined chronic thyroiditis; however, there was no difference in age at the time of diagnosis, lymph node metastasis, extrathyroid invasion, multicentricity, or TNM staging. The parent-offspring FNMTC group had more multicentricity than the SNMTC group. The sibling FNMTC group had only more females than the parent-offspring FNMTC group. Another study found that the sibling FNMTC group was associated with more Hashimoto's thyroiditis and extrathyroid extension than the parent-offspring FNMTC group [14]. Furthermore, in comparison to the SNMTC group, the sibling FNMTC group had more bilateral and multicentric tumors, while the parent-offspring FNMTC group showed more Hashimoto's thyroiditis, central lymph node metastasis, and T3 tumors [14].

Another type of comparison was performed by Rosario et al. [35] between index cases and their affected siblings who were screened by ultrasound. The index cases were found to have an older average age at the time of diagnosis, larger tumors, more lymph node metastases, and more extrathyroid invasion. In addition, McDonald et al. [34] reported that the index cases had a more aggressive disease because the other family members sought screening and they were diagnosed at an earlier stage of the disease. Recent studies reported that the index cases had larger tumor sizes and more lymph node metastases, and because of that, they required more aggressive surgeries and radioactive iodine therapy $[7,19]$. The index case in our report had the most aggressive disease (T4aN1bM0) in comparison to his siblings, and he required more extensive initial surgery in addition to 2 radioactive iodine ablation therapy doses of $100 \mathrm{mCi}$ each.

3.3. Prognosis (Recurrence, Disease-Free Survival, and Survival). In general, PTC has good survival rate with only $6 \%$ malignancy-related mortality at a median follow-up of 16 years in patients with nonmetastatic disease at presentation [36]. However, the controversy continues with the prognosis of FNMTC, where some studies showed that it has worse outcomes than SNMTC, while others did not show a difference. 
The rate of tumor recurrence in FNMTC was higher than that in SNMTC in a number of publications $[9,22,28,34]$, while it did not differ in others $[6,10,13,14,18,31,33]$.

After more than 6 years of follow-up of the reported family, the 2 members who had more aggressive tumors at presentation developed recurrent disease and required more aggressive surgeries and repeated radioactive iodine ablation therapy.

Only a few studies have assessed the disease-free survival (i.e., time to tumor recurrence), and it was shorter in FNMTC $[9,22,24,27,28]$.

Regarding mortality in association with FNMTC, most of the studies showed no difference from SNMTC $[1,7,9,10,13,14,22,24,31,33,37]$, except in the study carried out by McDonald et al. [34], where the FNMTC group had more significant mortality (3.3\% of 91 cases) than the SNMTC group $(0.4 \%$ of 521 cases) $(P=0.01)$.

Some studies tried to compare the different subtypes of FNMTC prognostically. For example, in one study [9], the disease-free survival was shorter in families with $\geq 3$ affected members than in families with only 2 victims $(P=0.045)$, while in other studies $[18,27,33]$, there was no difference. In addition, there was no difference between these two FNMTC subgroups in persistence or recurrence of the disease or in mortality [9]. Furthermore, there was no difference in the recurrence rate between sibling and parent-offspring subtypes of FNMTC $[14,27]$ or in a meta-analysis [8] comparing first-generation versus second-generation patients in families with FNMTC.

3.4. Pathogenesis and Genetic Background. Sometimes FNMTC is referred to as syndromic and nonsyndromic [20]. The syndromic group is not consistent with the true definition of the FNMTC, where FNMTC should not be a part of a familial syndrome, e.g., familial adenomatous polyposis, Werner syndrome, Cowden syndrome, Pendred syndrome, and Carney complex. Nonsyndromic FNMTC can be subdivided into different forms, namely, pure familial PTC with or without oxyphilia, familial PTC with papillary renal cell carcinoma, and familial PTC with multinodular goiter [20].

The genetic background of the nonsyndromic FNMTC is still unknown. However, based on the studied kindred, it is thought to be polygenic and autosomal dominant with incomplete penetrance and variable expression [20,38].

In addition, FNMTC demonstrated the phenomenon of genetic anticipation, where with successive generations, the disease is diagnosed at an earlier age with a more aggressive presentation $[14,16,39]$.

The genetic testing of the proband in the reported family did not show any genetic abnormality linked to his phenotype.

Research to identify FNMTC susceptibility genes is still ongoing. There are different potential genetic loci and genes that have been reported, such as multinodular goiter 1 (MNG1; 14q32) [40], thyroid carcinoma with oxyphilia (TCO; 19p13.2) [41], fPTC/papillary renal neoplasia (PRN; 1q21) [42], NMTC1 (2q21) [43], familial thyroid epithelial neoplasia (FTEN; 8p23.1-p22) [44], telomere-telomerase complex [45], TITF-1/NKX2 (which encodes thyroid transcription factor-1) [46], SRGAP1 (Slit- Robo Rho GTPase activating protein 1) genes [47], hyaluronan binding protein 2 (HABP2) [48], FOXE1 [49], SRRM2 (serine/arginine repetitive matrix 2 gene) [50], C14orf93 (RTFC) [51], mitogen-activated protein kinase kinase 5 (MAP2K5) [52], CHEK2 and ATM genes [53], ANXA3, NTN4, SERPINA1, FKBP10, PLEKHG5, P2RX5, SAPCD1 [54], and protection of telomeres 1 [POT1] gene [55].

The reason that, until now, no definite FNMTC susceptibility genes have been identified may be related to the inclusion of families with only 2 affected members in the genetic studies, while NMTC is not an uncommon condition in the general population. In addition, other modes of inheritance should be studied, such as the possible role of epigenetics [56].

3.5. Screening and Management Recommendations. There are no randomized controlled trials to guide the screening and management recommendations of FNMTC, and the available evidence only came from observational studies and expert opinion.

We need to take into consideration that recommending a screening program for any cancer condition requires the following[19]:

(1) To be directed to at-risk individuals

(2) To be able to discover the disease early in its course

(3) That early detection of the disease impacts the outcome

(4) To be cost-effective

Currently, the best available screening method is the ultrasound neck $[2,14,19,57]$, as there is no genetic test to definitely diagnose FNMTC and, for example, guide prophylactic thyroidectomy similar to familial medullary thyroid cancer [2].In addition, physical examination alone can miss many cases with nodular thyroid disease [19, 35]. Klubo-Gwiezdzinska et al. reported screening of 109 at-risk individuals, of which 55 (50.5\%) had thyroid nodules detected by ultrasound; however, only 7 cases $(7 / 55=12.7 \%)$ were palpable on physical examination.

Screening can detect FNMTC cases at an earlier stage of the disease; however, there is no consensus on at what age ultrasound screening should start and how frequently it should be performed. The youngest diagnosed patient with FNMTC was aged 8 years [13]. Some authors [14] recommended starting ultrasound screening from the age of 18 years and performing ultrasound screening yearly afterward, while others advised screening from the age of 10 years [2].

Most of the published management recommendations endorse more aggressive treatment, including total thyroidectomy, central lymph node dissection, radioactive iodine ablation therapy, and suppressive thyroid hormone treatment, in almost all patients with FNMTC $[9,10,14,58]$. In addition, the treatment of FNMTC in families with 3 or more affected members should be more aggressive, as they usually have a more hostile disease [7]. 
Capezzone et al. suggested that management recommendations for FNMTC should depend on controlled studies with comparable groups of FNMTC cases and SNMTC cases in their baseline characteristics [11].Furthermore, as the latest recommendations for less aggressive management of SNMTC were not assessed specifically in those with FNMTC, the authors suggested total thyroidectomy and radioactive iodine ablation therapy, especially for those belonging to families with 3 or more affected members [11].

Mazeh and Sippel [57] suggested an algorithm for screening and management of FNMTC where treatment decisions took into consideration the number of affected family members and the degree of aggressiveness of the disease within the family. They suggested performing a neck ultrasound screening on all family members starting from the age of 20 years or 10 years younger than the youngest affected family member. If there is no nodule, periodic ultrasound should be performed. If the person has benign nodules based on FNAB, prophylactic thyroidectomy could be performed if the family has an aggressive disease or has 3 or more affected members. They justified this recommendation based on families with FNMTC being more likely to have benign and malignant thyroid disease, which lowers the chance to detect cancer. If cancer was identified by FNAB, they recommend total thyroidectomy, routine central neck dissection in almost all patients, radioactive iodine ablation therapy if the family is known to have an aggressive disease or has 3 or more affected members, and thyroid hormone suppressive therapy in all patients.

Recently, Klubo-Gwiezdzinska et al. [19] authored a prospective study using neck ultrasound screening and reported a cancer detection rate of $4.6 \%$ in families with 2 members affected, which is similar to the general population $(4.5 \%)$ [1, 59]. However, in families with $\geq 3$ members affected, the detection rate was $22.7 \%(P=0.01)$.In addition, thyroid nodules were documented in $72.2 \%$ of the parents of index cases. Furthermore, the FNMTC detected in the screened cases was less aggressive than the index cases and required less aggressive surgery (hemithyroidectomy $23.5 \%$ versus $0 \% ; P=0.002)$ and a lower rate of radioactive iodine ablation therapy $(P \leq 0.001)$, with a better response to initial treatment than the index cases $(P=0.045)$. Based on their data, the authors recommended active screening using neck ultrasound only for families with 3 or more affected firstdegree relatives. The screening of first-degree relatives should include all generations relative to the index case and involve those at least aged 20 years or 10 years younger than the youngest diagnosed case with NMTC. Neck ultrasound should be performed every 2-3 years.

The latest American Thyroid Association (2015) guidelines did not recommend or discourage using neck ultrasound for FNMTC screening [60]. However, in view of the recent accumulating evidence, families with $\geq 3$ affected first-degree relatives should be considered eligible for ultrasound screening. In addition, to avoid overdiagnosis and overtreatment of clinically insignificant thyroid cancer cases in the population, it is better not to implement a screening program for families with only 2 affected members.
In the reported family, we performed neck ultrasound screening for siblings and parents. In addition, we advised them to start screening their children when they reach the age of 13 years (10 years less than the youngest diagnosed member in the family) and to repeat it yearly for the unaffected family members. All the family members diagnosed after the index case underwent total thyroidectomy with central lymph node dissection, including sibling 4 with microscopic PTC.

3.6. Future Research. Future research should focus on the identification of a solid molecular basis of FNMTC, as this is the best way to diagnose true familial cases. This will help to conduct further studies to develop evidence-based recommendations for patient management and follow-up and for family screening protocols.

Limiting the definition of FNMTC to include only kindred with 3 or more affected members may help in better characterization of the susceptibility genes, and this, in turn, helps to endorse more solid screening and management recommendations.

Because of the low prevalence of FNMTC, research and clinical centers in different countries should collaborate to have enough patients to obtain meaningful results.

\section{Conclusions}

FNMTC has many controversies in relation to its definition, clinicopathological aggressiveness, prognosis, treatment, and screening of at-risk family members. Different genetic mutations have been investigated; however, none of them was confirmed to be a source of the condition. Based on the available evidence, it is advisable to implement ultrasound neck screening only in families with 3 or more affected members and to be done yearly starting at age 10 years earlier than the youngest affected family member. In addition, the diagnosed cases in those families should have a lower threshold for a more aggressive management decision.

The multidisciplinary team of endocrinologists, surgeons, and genetics specialists at our institution recommended the same for the reported family.

FNMTC is an area that needs to be addressed in future research to resolve its ambiguity and controversial issues and to have screening and management recommendations based on high-quality evidence.

\section{Data Availability}

The data used to support the findings of this study are included within the article.

\section{Conflicts of Interest}

The authors declare that they have no conflicts of interest.

\section{References}

[1] W. Moses, J. Weng, and E. Kebebew, "Prevalence, clinicopathologic features, and somatic genetic mutation profile in 
familial versus sporadic nonmedullary thyroid cancer," Thyroid, vol. 21, no. 4, pp. 367-371, 2011.

[2] O. H. Clark, "Controversies in familial thyroid cancer 2014," Turkish Journal of Surgery, vol. 30, no. 2, pp. 62-66, 2014.

[3] M. Capezzone, C. Secchi, N. Fralassi et al., "Should familial disease be considered as a negative prognostic factor in micropapillary thyroid carcinoma?" Journal of Endocrinological Investigation, vol. 42, no. 10, pp. 1205-1213, 2019.

[4] C. D. Malchoff and D. M. Malchoff, "Familial nonmedullary thyroid carcinoma," Cancer Control, vol. 13, no. 2, pp. 106-110, 2006.

[5] N. D. Charkes, "On the prevalence of familial nonmedullary thyroid cancer in multiply affected kindreds," Thyroid, vol. 16, no. 2, pp. 181-186, 2006.

[6] K.-C. Loh, "Familial nonmedullary thyroid carcinoma: a meta-review of case series," Thyroid, vol. 7, no. 1, pp. 107-113, 1997.

[7] M. El Lakis, A. Giannakou, P. J. Nockel et al., "Do patients with familial nonmedullary thyroid cancer present with more aggressive disease? implications for initial surgical treatment," Surgery, vol. 165, no. 1, pp. 50-57, 2019.

[8] Y.-M. Zhou, H. Luo, J.-X. Gou et al., "Second generation of familial nonmedullary thyroid carcinoma: a meta-analysis on the clinicopathologic features and prognosis," European Journal of Surgical Oncology, vol. 43, no. 12, pp. 2248-2256, 2017.

[9] Y.-B. Zhang, X.-X. Wang, X.-W. Zhang et al., "Familial nonmedullary thyroid carcinoma," Chinese Medical Journal, vol. 131, no. 4, pp. 395-401, 2018.

[10] Y. S. Kim, M. Seo, S. H. Park, S. Y. Ju, and E. S. Kim, "Should total thyroidectomy Be recommended for patients with familial non-medullary thyroid cancer?" World Journal of Surgery, vol. 44, no. 9, pp. 3022-3027, 2020.

[11] M. Capezzone, E. Robenshtok, S. Cantara, and M. G. Castagna, "Familial non-medullary thyroid cancer: a critical review," Journal of Endocrinological Investigation, vol. 44, no. 5, pp. 943-950, 2020.

[12] D. W. Robinson and T. G. ORR, "Carcinoma of the thyroid and other diseases of the thyroid in identical twins," Archives of Surgery, vol. 70, no. 6, pp. 923-928, 1955.

[13] A. E. Pinto, G. L. Silva, R. Henrique et al., "Familial vs. sporadic papillary thyroid carcinoma: a matched-case comparative study showing similar clinical/prognostic behaviour," European Journal of Endocrinology, vol. 170, no. 2, pp. 321-327, 2014.

[14] L. Jiwang, L. Zhendong, L. Shuchun, H. Bo, and L. Yanguo, "Clinicopathologic characteristics of familial versus sporadic papillary thyroid carcinoma," Acta Otorhinolaryngologica Italica: organo ufficiale della Societa italiana di otorinolaringologia e chirurgia cervico-facciale, vol. 35 , no. 4 , pp. 234242, 2015.

[15] L. O'Connell, R. S. Prichard, E. O’Reilly, S. Skehan, D. Gibbons, and E. W. McDermott, "Running in the family: a rare diagnosis of familial papillary thyroid cancer," International Journal of Surgery Case Reports, vol. 16, pp. 64-66, 2015.

[16] M. Capezzone, S. Marchisotta, S. Cantara et al., "Familial nonmedullary thyroid carcinoma displays the features of clinical anticipation suggestive of a distinct biological entity," Endocrine-Related Cancer, vol. 15, no. 4, pp. 1075-1081, 2008.

[17] S. Lei, D. Wang, J. Ge et al., "Single-center study of familial papillary thyroid cancer in China: surgical considerations," World Journal of Surgical Oncology, vol. 13, no. 1, p. 115, 2015.

[18] E. Robenshtok, G. Tzvetov, S. Grozinsky-Glasberg et al., "Clinical characteristics and outcome of familial nonmedullary thyroid cancer: a retrospective controlled study," Thyroid, vol. 21, no. 1, pp. 43-48, 2011.

[19] J. Klubo-Gwiezdzinska, L. Yang, R. Merkel et al., "Results of screening in familial non-medullary thyroid cancer," Thyroid, vol. 27, no. 8, pp. 1017-1024, 2017.

[20] J. Guilmette and V. Nosé, "Hereditary and familial thyroid tumours," Histopathology, vol. 72, no. 1, pp. 70-81, 2018.

[21] V. Nosé, "Familial thyroid cancer: a review," Modern Pathology, vol. 24, no. S2, pp. S19-S33, 2011.

[22] S. Uchino, S. Noguchi, H. Kawamoto et al., "Familial nonmedullary thyroid carcinoma characterized by multifocality and a high recurrence rate in a large study population," World Journal of Surgery, vol. 26, no. 8, pp. 897-902, 2002.

[23] R. F. Grossman, S. H. Tu, Q. Y. Duh, A. E. Siperstein, F. Novosolov, and O. H. Clark, "Familial nonmedullary thyroid cancer," Archives of Surgery, vol. 130, no. 8, pp. 892-897, 1995.

[24] O. Alsanea, N. Wada, K. Ain et al., "Is familial non-medullary thyroid carcinoma more aggressive than sporadic thyroid cancer? A multicenter series," Surgery, vol. 128, no. 6, pp. 1043-1051, 2000.

[25] F. Triponez, M. Wong, C. Sturgeon et al., "Does familial nonmedullary thyroid cancer adversely affect survival?" World Journal of Surgery, vol. 30, no. 5, pp. 787-793, 2006.

[26] H. Mazeh, J. Benavidez, J. L. Poehls, L. Youngwirth, H. Chen, and R. S. Sippel, "In patients with thyroid cancer of follicular cell origin, a family history of nonmedullary thyroid cancer in one first-degree relative is associated with more aggressive disease," Thyroid, vol. 22, no. 1, pp. 3-8, 2012.

[27] Y. J. Park, H. Y. Ahn, H. S. Choi, K. W. Kim, D. J. Park, and B. Y. Cho, "The long-term outcomes of the second generation of familial nonmedullary thyroid carcinoma are more aggressive than sporadic cases," Thyroid, vol. 22, no. 4, pp. 356-362, 2012.

[28] X. Wang, W. Cheng, J. Li et al., "Endocrine tumours: familial nonmedullary thyroid carcinoma is a more aggressive disease: a systematic review and meta-analysis," European Journal of Endocrinology, vol. 172, no. 6, pp. R253-R262, 2015.

[29] H. Sezer, M. O. Demirkol, D. Yazici, Y. Kapran, and F. Alagöl, "The clinicopathologic characteristics of familial and sporadic papillary thyroid carcinoma in Turkish patients," Turkish Journal of Medical Sciences, vol. 44, no. 2, pp. 360-368, 2020.

[30] G. Lupoli, G. Vitale, M. Caraglia et al., "Familial papillary thyroid microcarcinoma: a new clinical entity," The Lancet, vol. 353, no. 9153, pp. 637-639, 1999.

[31] E. L. Maxwell, F. T. Hall, and J. L. Freeman, "Familial nonmedullary thyroid cancer: a matched-case control study," The Laryngoscope, vol. 114, no. 12, pp. 2182-2186, 2004.

[32] Y. Ito, M. Fukushima, T. Yabuta et al., "Prevalence and prognosis of familial follicular thyroid carcinoma," Endocrine Journal, vol. 55, no. 5, pp. 847-852, 2008.

[33] Y. Ito, K. Kakudo, M. Hirokawa et al., "Biological behavior and prognosis of familial papillary thyroid carcinoma," Surgery, vol. 145, no. 1, pp. 100-105, 2009.

[34] T. J. McDonald, A. A. Driedger, B. M. Garcia et al., "Familial papillary thyroid carcinoma: a retrospective analysis," Journal of Oncology, vol. 2011, Article ID 948786, 8 pages, 2011.

[35] P. W. Rosario, A. F. C. Mineiro Filho, B. S. S. Prates, L. C. O. Silva, R. X. Lacerda, and M. R. Calsolari, "Ultrasonographic screening for thyroid cancer in siblings of patients with apparently sporadic papillary carcinoma," Thyroid, vol. 22, no. 8, pp. 805-808, 2012.

[36] E. L. Mazzaferri and S. M. Jhiang, "Long-term impact of initial surgical and medical therapy on papillary and follicular 
thyroid cancer," The American Journal of Medicine, vol. 97, no. 5, pp. 418-428, 1994.

[37] F. Pitoia, G. Cross, M. E. Salvai, E. Abelleira, and H. Niepomniszcze, "Patients with familial non-medullary thyroid cancer have an outcome similar to that of patients with sporadic papillary thyroid tumors," Arquivos Brasileiros de Endocrinologia \& Metabologia, vol. 55, no. 3, pp. 219-223, 2011.

[38] A. J. Bauer, "Clinical behavior and genetics of nonsyndromic, familial nonmedullary thyroid cancer," Endocrine Tumor Syndromes and Their Genetics, vol. 41, pp. 141-148, 2013.

[39] A. Hillenbrand, J.-E. Varhaug, M. Brauckhoff et al., "Familial nonmedullary thyroid carcinoma-clinical relevance and prognosis. A European multicenter study," Langenbeck's Archives of Surgery, vol. 395, no. 7, pp. 851-858, 2010.

[40] G. R. Bignell, F. Canzian, M. Shayeghi et al., "Familial nontoxic multinodular thyroid goiter locus maps to chromosome 14q but does not account for familial nonmedullary thyroid cancer," The American Journal of Human Genetics, vol. 61, no. 5, pp. 1123-1130, 1997.

[41] F. Canzian, P. Amati, H. R. Harach et al., "A gene predisposing to familial thyroid tumors with cell oxyphilia maps to chromosome 19p13.2.2," The American Journal of Human Genetics, vol. 63, no. 6, pp. 1743-1748, 1998.

[42] C. D. Malchoff, M. Sarfarazi, B. Tendler et al., "Papillary thyroid carcinoma associated with papillary renal neoplasia: genetic linkage analysis of a distinct heritable tumor syndrome," The Journal of Clinical Endocrinology \& Metabolism, vol. 85, no. 5, pp. 1758-1764, 2000.

[43] J. D. McKay, F. Lesueur, L. Jonard et al., "Localization of a susceptibility gene for familial nonmedullary thyroid carcinoma to chromosome 2q21," The American Journal of Human Genetics, vol. 69, no. 2, pp. 440-446, 2001.

[44] B. M. Cavaco, P. F. Batista, L. G. Sobrinho, and V. Leite, "Mapping a new familial thyroid epithelial neoplasia susceptibility locus to chromosome 8p23.1-p22 by high-density single-nucleotide polymorphism genome-wide linkage analysis," The Journal of Clinical Endocrinology \& Metabolism, vol. 93, no. 11, pp. 4426-4430, 2008.

[45] M. Capezzone, S. Cantara, S. Marchisotta et al., "Telomere length in neoplastic and nonneoplastic tissues of patients with familial and sporadic papillary thyroid cancer," The Journal of Clinical Endocrinology \& Metabolism, vol. 96, no. 11, pp. E1852-E1856, 2011.

[46] E. S. W. Ngan, B. H. H. Lang, T. Liu et al., "A germline mutation $(\mathrm{A} 339 \mathrm{~V})$ in thyroid transcription factor-1 (TITF-1/ NKX2.1) in patients with multinodular goiter and papillary thyroid carcinoma," Journal of the National Cancer Institute: Journal of the National Cancer Institute, vol. 101, no. 3, pp. 162-175, 2009.

[47] H. He, A. Bronisz, S. Liyanarachchi et al., "SRGAP1Is a candidate gene for papillary thyroid carcinoma susceptibility," The Journal of Clinical Endocrinology \& Metabolism, vol. 98, no. 5, pp. E973-E980, 2013.

[48] S. K. Gara, L. Jia, M. J. Merino et al., "GermlineHABP2Mutation causing familial nonmedullary thyroid cancer," New England Journal of Medicine, vol. 373, no. 5, pp. $448-455,2015$.

[49] J. S. Pereira, J. G. da Silva, R. A. Tomaz et al., "Identification of a novel germline FOXE1 variant in patients with familial nonmedullary thyroid carcinoma (FNMTC)," Endocrine, vol. 49, no. 1, pp. 204-214, 2015.

[50] J. Tomsic, H. He, K. Akagi et al., "A germline mutation in SRRM2, a splicing factor gene, is implicated in papillary thyroid carcinoma predisposition," Scientific Reports, vol. 5, no. 1, Article ID 10566, 2015.

[51] C. Liu, Y. Yu, G. Yin et al., "C14orf93 (RTFC) is identified as a novel susceptibility gene for familial nonmedullary thyroid cancer," Biochemical and Biophysical Research Communications, vol. 482, no. 4, pp. 590-596, 2017.

[52] F. Ye, H. Gao, L. Xiao et al., "Whole exome and target sequencing identifies MAP2K5 as novel susceptibility gene for familial non-medullary thyroid carcinoma," International Journal of Cancer, vol. 144, no. 6, pp. 1321-1330, 2019.

[53] Y. Wang, S. Liyanarachchi, K. E. Miller et al., "Identification of rare variants predisposing to thyroid cancer," Thyroid, vol. 29, no. 7, pp. 946-955, 2019.

[54] M. Sarquis, D. C. Moraes, L. Bastos-Rodrigues et al., "Germline mutations in familial papillary thyroid cancer," Endocrine Pathology, vol. 31, no. 1, pp. 14-20, 2020.

[55] A. Srivastava, B. Miao, D. Skopelitou et al., "A germline mutation in the POT1 gene is a candidate for familial nonmedullary thyroid cancer," Cancers, vol. 12 , no. 6, p. 1441, 2020.

[56] S. A. Ammar, W. M. Alobuia, and E. Kebebew, "An update on familial nonmedullary thyroid cancer," Endocrine, vol. 68, no. 3, pp. 502-507, 2020.

[57] H. Mazeh and R. S. Sippel, "Familial nonmedullary thyroid carcinoma," Thyroid, vol. 23, no. 9, pp. 1049-1056, 2013.

[58] R. S. Sippel, N. R. Caron, and O. H. Clark, "An evidence-based approach to familial nonmedullary thyroid cancer: screening, clinical management, and follow-up," World Journal of Surgery, vol. 31, no. 5, pp. 924-933, 2007.

[59] L. Furuya-Kanamori, K. J. L. Bell, J. Clark, P. Glasziou, and S. A. R. Doi, "Prevalence of differentiated thyroid cancer in autopsy studies over six decades: a meta-analysis," Journal of Clinical Oncology, vol. 34, no. 30, pp. 3672-3679, 2016.

[60] B. R. Haugen, E. K. Alexander, K. C. Bible et al., "2015 American thyroid association management guidelines for adult patients with thyroid nodules and differentiated thyroid cancer: the American thyroid association guidelines task force on thyroid nodules and differentiated thyroid cancer," Thyroid, vol. 26, no. 1, pp. 1-133, 2016. 